\title{
PENGUKURAN TINGKAT PEMAHAMAN MAHASISWA TERHADAP VISI MISI PROGRAM STUDI PENDIDIKAN BIOLOGI FKIP UNTAN
}

\author{
MEASURING THE LEVEL OF STUDENTS' UNDERSTANDING OF \\ THE VISION-MISSION IN THE BIOLOGY EDUCATION STUDY \\ PROGRAM OF FKIP UNTAN
}

\author{
Andri Maulidi, Syamswisna, Entin Daningsih, Eka Ariyati, Reni Marlina* \\ Biology Education Study Program, Faculty of Teacher Training and Education, Tanjungpura University. \\ Jl. Prof. Dr. H. Hadari Nawawi, Pontianak, Indonesia \\ *Corresponding author: reni.marlina@fkip.untan.ac.id
}

\begin{abstract}
The Implementation of education in Higher Education must have the vision and mission to achieve a certain goal. The result of the vision and mission statement is socialized to get feedback as an evaluation and perfection of the vision and mission. The achievement of vision and mission that have been determined must be known, understood, and implemented by all academicians including students. This research was conducted to measure the level of students' understanding of the vision and mission of Biology Education Study Program of FKIP Untan. This research used qualitative approach with descriptive study. The subjects in this research were 246 students of Biology Education Study Program of FKIP Untan class of 2015, 2016, and 2017. The research instrument used was a questionnaire with closed and open statement. The results of this study indicated that in general the students have understood the vision and mission well. Data analysis showed that $236(95,93 \%)$ students have read vision and mission, 190 (77,24\%) and 204 (82,93\%) students knew about vision and mission, $203(33,44 \%), 101(64 \%)$ students were the highest percentage of students who read the vision and mission in standing banner or class and in academic guidance book. Furthermore, 162 students (65.85\%) agreed that they have been well informed about the vision and mission, 165 students $(67.07 \%)$ agreed that they have understood the vision and mission, 173 students (70.33\%) agreed with the existence of vision and mission, and 159 students $(64.63 \%)$ agreed that the vision and mission were used as references.
\end{abstract}

Keywords: level of understanding, vision and mission

\section{PENDAHULUAN}

Setiap organisasi termasuk diantaranya sebuah Program Studi di suatu Perguruan Tinggi tentunya memiliki faktor yang mengarahkan pada sukses atau gagalnya organisasi tersebut. Untuk bisa dikatakan sukses setiap program studi pastilah memiliki visi dan misi. Definisi visi menurut Ancok (2007), visi adalah suatu pernyataan yang berisikan arahan yang jelas tentang apa yang akan diperbuat oleh perusahaan di masa yang akan datang. Sedangkan berdasarkan pendapat dari Wibisono (2006), visi merupakan rangkaian kalimat yang menyatakan cita-cita atau impian sebuah organisasi yang akan dicapai di masa depan. Sedangkan pengertian misi menurut Wibisono (2006), merupakan rangkaian kalimat yang menyatakan tujuan atau alasan eksistensi organisasi, yang memuat apa yang disediakan oleh organisasi kepada masyarakat, baik berupa produk ataupun jasa.

Visi dan Misi suatu lembaga memiliki peran yang sangat penting untuk pengembangan lembaga tersebut. Pentingnya visi misi juga tergambarkan beberapa Perguruan Tinggi yang telah melakukan pengukuran visi misi seperti Dewi (2014), Sunardi dan Sudarwati (2014). Pentingnya peran visi dan misi suatu lembaga membuat Badan Akreditasi Nasional (BAN) menempatkan visi dan misi ini pada standar paling awal atau standar satu pada borang akreditasi. Pernyataan visi dan misi harus dibuat jelas, realistik untuk dilakukan dan dicapai serta harus disertai dengan tujuan dan sasaran tertentu. Selain itu perlu dilakukan sosialisasi kepada civitas akademika termasuk didalamnya mahasiswa. Pada matrik penilaian borang akreditasi, sosialisasi visi misi dikatakan baik apabila visi, misi, tujuan dan sasaran lembaga dapat dipahami dengan baik oleh seluruh civitas akademika dan tenaga kependidikan. Apabila sebagian civitas akademika kurang memahami atau tidak memahami visi, misi, tujuan dan sasaran yang dirumuskan maka sosialisasi visi dan misi ini dikatakan kurang baik dan dikhawatirkan dapat memperlambat pencapaian visi misi tersebut.

Sosialisasi visi, misi, tujuan dan kurikulum Program Studi Pendidikan Biologi FKIP Universitas 
Tanjungpura sudah dilakukan melalui berbagai media seperti leaflet Program Studi, standing banner, buku pedoman akademik, penjelasan pengelola program studi atau dosen dan dihalaman website Program Studi Pendidikan Biologi FKIP Universitas Tanjungpura. Visi dan Misi di lembaga pendidikan, baik ditingkat fakultas maupun Program Studi disusun saling terkait diantaranya dan melibatkan pemangku kepentingan (stakeholder). Analisis keterkaitan antara visi misi Program Studi Pendidikan Biologi dievaluasi secara berkala lewat rapat, pertemuan unit jaminan mutu, dan evaluasi kurikulum yang dilakukan secara periodik.

Adapun proses pembuatan visi misi yaitu pada awalnya visi dan misi program studi Pendidikan Biologi FKIP Universitas Tanjungpura disusun dengan mempertimbangkan berbagai faktor seperti sejarah awal pendirian program studi Pendidikan Biologi FKIP Universitas Tanjungpura, perkembangan ilmu pengetahuan, teknologi dan seni (IPTEK) serta berpedoman pada visi, misi, tujuan dan sasaran FKIP dan visi, misi, tujuan dan sasaran Universitas Tanjungpura. Penetapan visi dan misi program studi Pendidikan Biologi FKIP Universitas Tanjungpura tentunya dilanjutkan dengan proses sosialisasi visi dan misi tersebut dengan berbagai upaya diantaranya (1) sosialisasi kepada dosen melalui rapat-rapat rutin di jurusan maupun fakultas, (2) sosialisasi kepada mahasiswa melalui kegiatan kemahasiswaan dan perkuliahan, (3) sosialisasi kepada pemangku kepentingan atau stakeholder yang dilakukan pada saat rapat atau undangan dalam menjalin kerjasama, (4) sosialisasi kepada tenaga kependidikan, dilakukan dalam rapat di tingkat jurusan dan fakultas, serta (5) sosialisasi pada masyarakat yang dilakukan melalui website program studi, leaflet dan banner.

Berdasarkan upaya sosialisasi yang telah dilakukan, peneliti tertarik untuk melakukan penelitian tingkat pemahaman mahasiswa terhadap visi misi program studi Pendidikan Biologi FKIP Universitas Tanjungpura yang diperlukan dalam melengkapi borang akreditasi. Informasi ini berguna sebagai feedback untuk perbaikan, pengembangan dan penyempurnaan visi misi Program Studi Pendidikan Biologi FKIP Universitas Tanjungpura.

\section{METODE PENELITIAN}

Jenis penelitian ini merupakan penelitian deskriptif. Menurut Sukmadinata (2013) penelitian deskriptif adalah suatu penelitian yang paling dasar. Penelitian deskriptif tidak memberikan perlakuan, manipulasi atau pengubahan pada variabel-variabel bebas, tetapi menggambarkan suatu kondisi apa adanya.

Pada penelitian ini data yang dibutuhkan adalah data primer dan data sekunder. Data sekunder diperoleh dari referensi dan informasi yang didokumentasikan oleh program studi Pendidikan Biologi FKIP Universitas Tanjungpura. Data sekunder yang diperlukan antara lain data jumlah mahasiswa aktif. Subjek dalam penelitian ini adalah 246 orang mahasiswa aktif program studi pendidikan biologi dari angkatan 2015, 2016, dan 2017.

Data primer merupakan data yang diperoleh langsung dari sumbernya berupa tanggapan atau pendapat responden mengenai suatu permasalahan yang diajukan dalam penelitian. Dalam hal ini data yang diambil berupa angket tentang tingkat pemahaman mahasiswa tentang visi dan misi program studi Pendidikan Biologi FKIP Universitas Tanjungpura. Angket merupakan daftar pertanyaan yang diberikan kepada subjek penelitian untuk memberikan respon sesuai dengan permintaan peneliti (Riduwan, 2012). Hasil angket dianalisis menggunakan analisis statistik deskriptif. Menurut Sudrajat (2009) analisis statistik deskriptif adalah penggunaan rumus prosentase dalam pengolahan data angket dalam bentuk deskriptif.

\section{HASIL DAN PEMBAHASAN}

Tingkat pemahaman mahasiswa terhadap visi misi Program Studi Pendidikan Biologi FKIP Untan dapat dilihat dari 15 butir pertanyaan yang ada pada angket. Berdasarkan hasil angket, pertanyaan pertama berkaitan dengan lama mengenal program studi. Sebanyak 74 (30,08\%) mahasiswa mengenal program studi pendidikan biologi selama kurang dari satu tahun dan $172(69,92 \%)$ mahasiswa mengenal program studi pendidikan biologi selama satu hingga lima tahun. Pada pertanyaan kedua yaitu mengenai pernah atau belum pernah membaca visi misi prodi. Sebanyak 236 $(95,93 \%)$ mahasiswa pernah membaca visi misi prodi pendidikan biologi, sedangkan 10 (4,07\%) mahasiswa belum pernah membaca visi misi prodi pendidikan biologi. Adanya persentasi mahasiswa yang tidak pernah membaca visi misi prodi menunjukkan bahwa terdapat mahasiswa yang kurang memperhatikan apa yang ada disekitarnya. Visi misi prodi terdapat di setiap ruang kelas prodi pendidikan biologi, buku panduan akademik dan lain-lain. Seharusnya tidak ada persentase mahasiswa yang belum pernah membaca visi misi prodi.

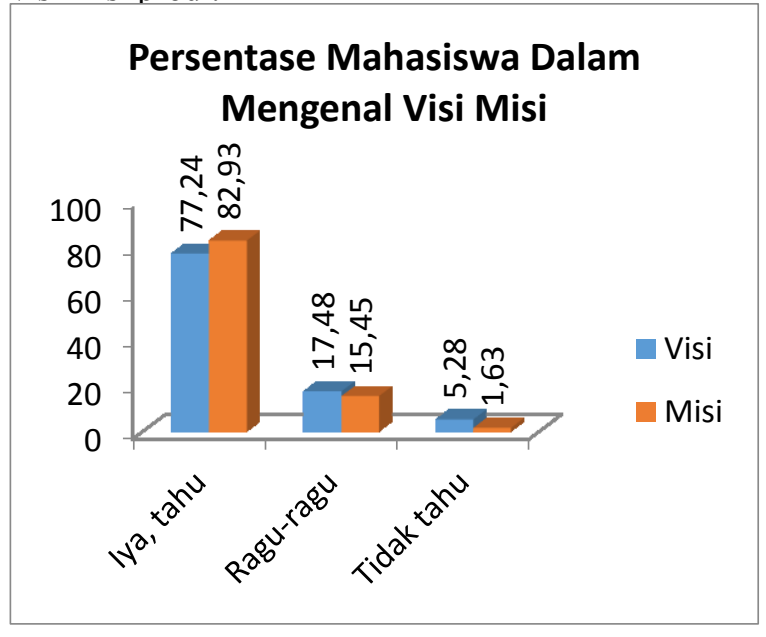

Gambar 1. Persentase mahasiswa dalam mengenal visi misi

Pada Gambar 1 menunjukkan bahwa jumlah mahasiswa yang tahu tentang visi sebanyak 190 
(77,24\%), ragu-ragu $43(17,48 \%)$, dan tidak tahu sebanyak $13(5,28 \%)$ mahasiswa. Jumlah mahasiswa yang tahu tentang misi sebanyak 204 (82,93\%), raguragu sebanyak $38(15,45 \%)$ dan tidak tahu sebanyak 4 $(1,63 \%)$ mahasiswa.

Selanjutnya pertanyaan dimana mahasiswa mendapatkan informasi terkait visi misi prodi dapat dilihat pada gambar 2. Paling banyak sebesar 203 $(33,44 \%)$ mahasiswa mendapatkan informasi visi misi pada media papan pengumuman di prodi dan kelas, sebanyak $101(16,64 \%)$ pada media buku pedoman akademik, dan sebanyak 99 (16,31\%) mahasiswa melihat pada website program studi. Untuk persentase terendah, sebanyak tiga mahasiswa memilih lain-lain yaitu pada kalender program studi pendidikan biologi. Sosialisasi visi misi yang dilakukan bertujuan untuk mendapatkan feedback sebagai bahan perbaikan dan penyempurnaan visi misi Program Studi Pendidikan Biologi FKIP Untan.

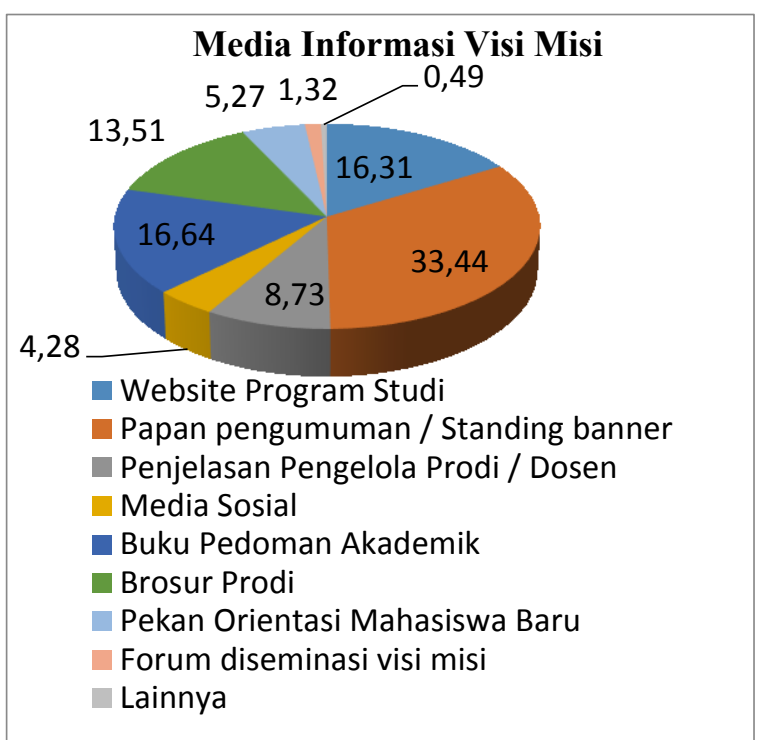

Gambar 2. Persentase Media Informasi yang digunakan mahasiswa mengetahui visi-misi

Hasil angket pertanyaan nomor enam hingga sembilan dapat dilihat pada Tabel 1. Pertanyaan nomor enam terkait apakah mahasiswa sudah mendapatkan penjelasan visi misi dengan baik, persentase tertinggi sebanyak $162 \quad(65,85 \%)$ mahasiswa menjawab setuju bahwa penjelasan visi misi sudah baik dan memadai, sedangkan persentase terendah sebanyak $1(0,41 \%)$ mahasiswa mengatakan sangat tidak setuju.

Tabel 1. Hasil persentase angket pertanyaan nomor 6-9.

\begin{tabular}{cccccc}
\hline No & TT (\%) & $\begin{array}{c}\text { STS } \\
(\%)\end{array}$ & $\begin{array}{c}\text { TS } \\
(\%)\end{array}$ & S (\%) & $\begin{array}{c}\text { SS } \\
(\%)\end{array}$ \\
\hline 6. & 10,98 & 0,41 & 11,38 & 65,85 & 11,38 \\
7. & 11,79 & 0,41 & 13,01 & 67,07 & 7,72 \\
8. & 2,44 & 0,41 & 1,22 & 70,33 & 25,61 \\
9. & 13,41 & 2,03 & 10,57 & 64,63 & 9,35 \\
\hline
\end{tabular}

$$
\begin{array}{lll}
\text { Keterangan: } & \text { TT } & =\text { Tidak Tahu } \\
& \text { STS } & =\text { Sangat Tidak Setuju } \\
\text { TS } & =\text { Tidak Setuju } \\
\text { S } & =\text { Setuju } \\
\text { SS } & =\text { Sangat Setuju }
\end{array}
$$

Pertanyaan berikutnya yaitu mahasiswa memahami visi misi dengan baik dan memadai. Hasil angket tersebut yaitu sebanyak $165 \quad(67,07 \%)$ mahasiswa menjawab setuju dan persentase terendah menjawab sangat tidak setuju $1(0,41 \%)$ mahasiswa. Pada pertanyaan nomor delapan terkait apakah mahasiswa menyetujui isi dari visi misi program studi pendidikan biologi FKIP Untan. Hasil angket tersebut menunjukkan bahwa $173 \quad(70,33 \%)$ mahasiswa menjawa setuju terkait isi visi misi prodi sedangkan persentase terendah pada sangat tidak setuju dengan persentase 0,41\%. Pertanyaan nomor sembilan berkaitan dengan dalam pelaksanaan kegiatan, Program Studi Pendidikan Biologi telah menggunakan visi misi sebagai acuan. Sebanyak 159 $(64,63 \%)$ mahasiswa setuju, sedangkan persentase terendah pada jawaban STS sebanyak 5 (2,03\%) mahasiswa.

Berdasarkan hasil dari keempat pertanyaan ini dapat diketahui bahwa sebagian besar informasi visi misi sudah baik dan memadai, mahasiswa paham dengan visi misi serta mahasiswa setuju dengan isi dari visi misi program studi. Hal ini tidak terlepas dari kesuksesan dalam sosialisasi visi misi Program Studi Pendidikan Biologi yang dilakukan dalam berbagai kesempatan. Hal ini pun dapat terlihat dari persentase pertanyaan nomor lima terkait media informasi yang digunakan untuk sosialisasi visi misi.

Pertanyaan angket yang ke 10 yaitu mengenai berapa persen visi misi Program Studi Pendidikan Biologi sudah tercapai. Dari 246 reponden, 180 $(73,17 \%)$ mahasiswa memilih ketercapaian antara $50 \%$ hingga $80 \%, 46(18,7 \%)$ mahasiswa memilih kurang dari 50\%, dan $20(8,13 \%)$ mahasiswa memilih ketercapaian visi misi lebih dari $80 \%$. Ketercapaian visi misi ini juga tidak terlepas dari sasaran pengembangan program studi. Pemantapan daya saing nasional dapat dilihat bahwa Program Studi Pendidikan Biologi saat ini sudah mampu mendapatkan akreditasi B BAN PT tahun 2016-2021. Pencapaian di tingkat nasional lainnya melalui penelitian dan daya saing lulusan untuk studi lanjut.

Pertanyaan berikutnya mengenai ketersediaan sumberdaya di Program Studi Pendidikan Biologi untuk menunjang tercapainya visi misi. Sebanyak 96 $(39,02 \%)$ mahasiswa menjawab baik, kemudian 74 (30,08\%) mahasiswa menjawab cukup, 70 (28,46\%) mahasiswa menjawab kurang, dan 6 (2,44\%) mahasiswa menjawab sangat baik. Mahasiswa yang memilih cukup dan kurang jika dijumlahkan keduanya maka akan melebihi 50\%. Kegiatan Open Talk yang rutin diadakan mahasiswa dan program studi untuk diskusi dengan dosen, mahasiswa dan alumni, 
mengungkapkan bahwa fasilitas program studi sudah cukup memadai, hanya saja masih terdapat keterbatasan jumlah seperti pada beberapa alat laboratorium. Hal ini akan terus ditindaklanjuti oleh pihak program studi dan kepala laboratorium untuk terus meningkatkan kualitas dan kuantitas dari sumberdaya yang ada di Program Studi Pendidikan Biologi.

Pertanyaan yang ke 12 yaitu mengenai keterlibatan mahasiswa dalam penyusunan visi misi program studi. Sebanyak $162(65,85 \%)$ mahasiswa menjawab tidak, sedangkan selebihnya yaitu 84 $(34,15 \%)$ mahasiswa menjawab iya. Perbedaan persentase ini dikarenakan tidak seluruh mahasiswa dilibatkan dalam penyusunan visi misi. Mahasiswa angkatan 2017 merupakan mahasiswa baru sehingga belum dilibatkan dalam penyusunan visi misi Program Studi Pendidikan Biologi. Penyusunan visi misi sebaiknya dilakukan bersama dengan orang-orang yang berkepentingan untuk melaksanakannya (Sukaningtyas, 2017). Hal ini dilakukan agar visi misi yang dirancang bersama dapat dipahami dengan baik (Bainbridge, 2007). Saat visi misi tidak disusun bersama maka akan menimbulkan kalimat yang kurang dipahami atau belum ada kesamaan memaknai visi misi tersebut (Gurley et al., 2014; Ahanhanzo et al., 2006).

Dalam menyusun visi misi Program Studi Pendidikan Biologi, melibatkan pakar-pakar, staf dosen, dan pemangku kepentingan terkait. Dalam menyusun visi misi tersebut, dilakukan analisis evaluasi diri, benchmarking, memperhatikan masukan stakeholder serta mengacu pada kebijakan universitas, fakultas, dan jurusan.

Hasil angket untuk pertanyaan nomor 13 yang berkaitan dengan keterlibatan mahasiswa sebagai team work dalam mencapai visi misi Program Studi Pendidikan Biologi. Sebanyak $133 \quad(54,07 \%)$ mahasiswa menjawab iya, $86(34,96 \%)$ mahasiswa ragu-ragu, dan 27 (10,98\%) mahasiswa menjawab tidak. Hal ini menunjukkan bahwa mahasiswa yang menjawab tidak, masih belum paham tentang perannya sebagai mahasiswa dalam pencapaian visi misi. Hasil ini menggiring untuk terus dilakukannya sosialisasi agar dalam visi misi ini dapat tercermin dalam kegiatan harian seluruh civitas akademika Program Studi Pendidikan Biologi FKIP Untan.

Pertanyaan berikutnya berkaitan dengan cerminan visi misi Program Studi Pendidikan Biologi FKIP Untan (Gambar 3). Cerminan visi misi Program Studi paling tinggi dipilih mahasiswa pada kurikulum sebanyak 177 (22,1\%), diikuti pada proses pembelajaran dipilih sebnayak $157 \quad(19,6 \%)$ mahasiswa, $107 \quad(13,36 \%)$ mahasiswa memilih pengabdian kepada masyarakat dan yang terendah sebanyak $9(1,12 \%)$ memilih SOP dan $3(0,37 \%)$ memilih lainnya. Visi misi Program Studi Pendidikan Biologi diimplementasikan dalam kurikulum berbasis
KKNI, serta ditunjang dengan beberapa supporting system (SDM, sarana prasarana, sistem informasi, penelitian dosen, mahasiswa, kompetensi lulusan, dan lainnya).

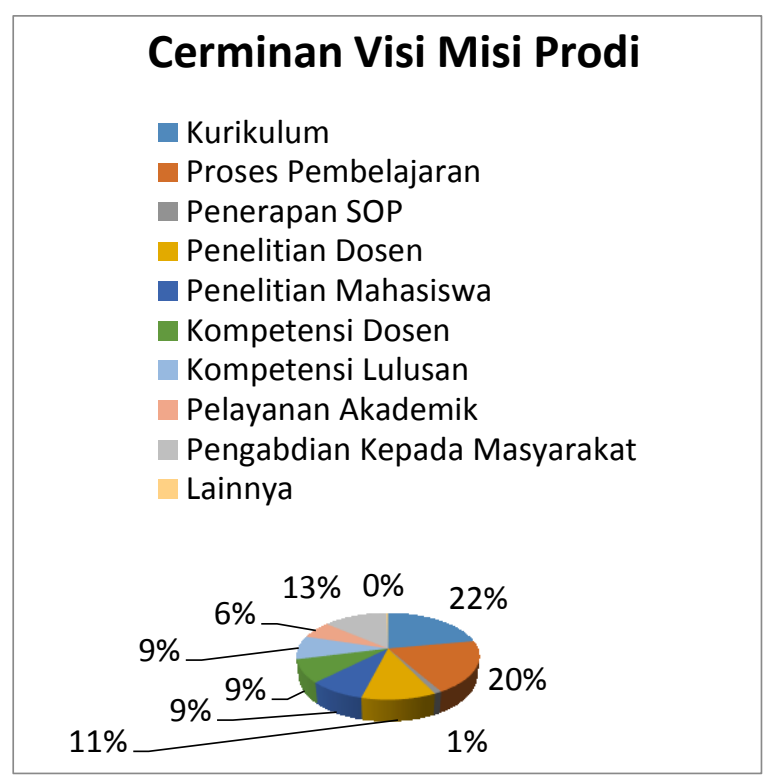

Gambar 3. Cerminan visi misi Program Studi Pendidikan Biologi

Pertanyaan terakhir yaitu yang ke 15 mengenai apakah masih perlu dilakukan sosialisasi kembali kepada seluruh civitas akademika, alumni serta stake holder. Sebanyak 125 (50,81\%) dan 99 (40,24\%) mahasiswa mengatakan setuju dan sangat setuju untuk dilakukan sosialisasi kembali visi misi Program Studi Pendidikan Biologi. Sebanyak 11 (4,47\%) mahasiswa memilih tidak tahu, $6(2,44 \%)$ mahasiswa memilih tidak setuju, dan $5(2,03 \%)$ mahasiswa memilih sangat tidak setuju jika dilakukan sosialisasi visi misi kembali. Sosialisasi yang baik harus dilakukan secara berulang. Menurut Sukaningtyas dkk., (2017) menyatakan bahwa upaya pemahaman visi misi membutuhkan perulangan agar benar-benar dapat dipahami.

\section{SIMPULAN}

Tingkat pemahaman visi misi mahasiswa Program Studi Pendidikan Biologi yaitu sebanyak 236 (95,93\%) mahasiswa pernah membaca visi misi. Sebanyak 190 (77,24\%) dan 204 (82,93\%) mahasiswa mengetahui visi dan misi. Sejumlah 203 (33,44\%), $101(16,64 \%)$ mahasiswa merupakan persentase tertinggi membaca visi misi di standing banner atau kelas dan di buku pedoman akademik. Hasil sosialisasi menunjukkan bahwa mahasiswa sudah memahami visi, misi Program Studi Pendidikan Biologi dengan baik.

Saran untuk sosialisasi visi misi berikutnya harus tetap dilaksanakan baik pada mahasiswa maupun dosen, tenaga kependidikan dan stakeholder. 


\section{UCAPAN TERIMAKASIH}

Terimakasih disampaikan untuk Universitas Tanjungpura yang telah memberikan pendanaan melalui dana DIPA. Terimakasih juga diucapkan kepada Program Studi Pendidikan Biologi serta mahasiswa angkatan 2015, 2016, dan 2017 yang telah terlibat menjadi subjek dalam penelitian ini.

\section{DAFTAR PUSTAKA}

Ahanhanzo, J., Odushin, D.E \& Bibi-Adelakoun, A. (2006). Building a Vision for Education in Benin. Prospects, 36(1), 9-21.

Ancok, D. (1995). Revitalisasi Sumber Daya Manusia dalam Era Perubahan. Kelola: Gadjah Mada University Business Review (8), 104-117.

Bainbridge, S. (2007). Creating A Vision for Your School, Moving from Purpose to Practice. London: Paul Chapman Publishing, A SAGE Publications Company.

Dewi, Y.R. (2014). Pemahaman Karyawan Terhadap Visi, Misi Dan Tujuan FIKOM UPDM. Wacana, 13(3), 246-255
Gurley, D.K., Peters, G.B., Collins, L. Fifolt, M. (2015). Mission, Vision, Values, and Goals: An Exploration of Key Organizational Statements And Daily Practice In Schools. J Educ Change, 16, 217.

Riduwan. (2012). Skala Pengukuran VariabelVariabel Penelitian. Bandung: Alfabeta.

Sudrajat, S. (2009). Dasar-Dasar Penelitian Ilmiah. Bandung: Pustaka Setia.

Sukaningtyas, D., Satori, D., \& Sa'ud, U.S. (2017). Pengembangan Kapasitas Manajemen Sekolah Dalam Membangun Pemahaman Visi dan Misi. Cakrawala Pendidikan, 36(2), 257-266.

Sukmadinata, N.S. (2013). Metode Penelitian Pendidikan. Bandung : PT Remaja Rosdakarya.

Sunardi, D. \& Sudarwati, W. (2014). Pengukuran Tingkat Pemahaman Civitas Akademika Terhadap Visi Misi Jurusan Teknik Industri. Jurnal Integrasi Sistem Industri UMJ, 1(2), 1-12.

Wibisono, D. (2006). Manajemen Kinerja, Konsep, Desain, dan Teknik Perusahaan. Jakarta: Erlangga. 